\title{
A Serological Point-of-Care Test for the Detection of IgG Antibodies against Ebola Virus in Human Survivors
}

Polina Brangel, ${ }^{\dagger}$ Ariel Sobarzo, ${ }^{\ddagger}$ Claudio Parolo, ${ }^{\S}$ Benjamin S. Miller, ${ }^{\S}$ Philip D. Howes, ${ }^{\dagger}$ Sigal Gelkop, ${ }^{\ddagger}$

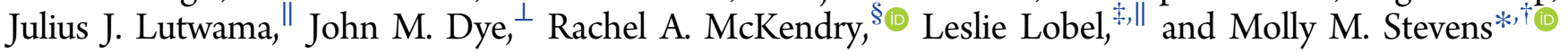

${ }^{\dagger}$ Department of Materials, Department of Bioengineering and Institute for Biomedical Engineering, Imperial College London, London SW7 2AZ, U.K.

${ }^{\ddagger}$ Department of Microbiology, Immunology and Genetics, Faculty of Health Sciences, Ben-Gurion University of the Negev, Beer-Sheva 8410501, Israel

${ }^{\S}$ London Centre for Nanotechnology and Div. of Medicine, University College London, London WC1E 6B, U.K.

"Department of Arbovirology, Emerging and Re-emerging Infection, Uganda Virus Research Institute, Entebbe P.O Box 49, Uganda

${ }^{\perp}$ Virology Division, US Army Medical Research Institute of Infectious Diseases, Fort Detrick, Frederick, Maryland 21702, United States

Supporting Information

ABSTRACT: Ebola virus disease causes widespread and highly fatal epidemics in human populations. Today, there is still great need for point-of-care tests for diagnosis, patient management and surveillance, both during and post outbreaks. We present a point-of-care test comprising an immunochromatographic strip and a smartphone reader, which detects and semiquantifies Ebola-specific antibodies in human survivors. We developed a Sudan virus glycoprotein monoplex platform and validated it using sera from 90 human survivors and 31 local noninfected

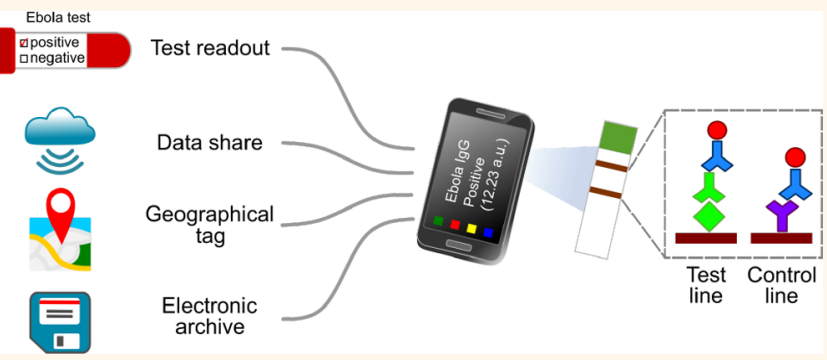
controls. The performance of the glycoprotein monoplex was $100 \%$ sensitivity and $98 \%$ specificity compared to standard whole antigen enzyme-linked immunosorbent assay (ELISA), and it was validated with freshly collected patient samples in Uganda. Moreover, we constructed a multiplex test for simultaneous detection of antibodies against three recombinant Sudan virus proteins. A pilot study comprising 15 survivors and 5 noninfected controls demonstrated sensitivity and specificity of $100 \%$ compared to standard ELISA. Finally, we developed a second multiplex subtype assay for the identification of exposure to three related EVD species: Sudan virus, Bundibugyo virus and Ebola virus (formerly Zaire) using recombinant viral glycoprotein. This multiplex test could distinguish between the host's immunity to specific viral species and identify cross-reactive immunity. These developed serological platforms consisted of capture ligands with high specificity and sensitivity, in-house developed strips and a compatible smartphone application. These platforms enabled rapid and portable testing, data storage and sharing as well as geographical tagging of the tested individuals in Uganda. This platform holds great potential as a field tool for diagnosis, vaccine development, and therapeutic evaluation.

KEYWORDS: Ebola virus disease, serological point-of-care, diagnostic test, lateral flow, smartphone reader, IgG antibodies, multiplex

E bola virus, a member of the filovirade family, is the pathogen responsible for the viral hemorrhagic Ebola virus disease (EVD). ${ }^{1}$ Over time, five distinct species of the ebolavirus genus have been detected, four of which are etiological agents of EVD: Ebola virus (EBOV), Sudan virus (SUDV), Bundibugyo virus (BDBV), and Tä Forest virus. ${ }^{2}$ This RNA negative strand virus genome encodes seven structural proteins, namely: nucleoprotein (NP), polymerase cofactor (VP35), matrix protein (VP40), glycoprotein (GP), replicationtranscription protein (VP30), minor matrix protein (VP24), and
RNA polymerase (L). ${ }^{1}$ Out of these, the viral protein GP is the most abundant protein expressed on the viral surface, and induces the primary immune response mechanism in the host. ${ }^{3}$

Over the past decade, the frequency and amplitude of EVD outbreaks have been vastly increased. ${ }^{4}$ The high-risk of this pathogen was recently exemplified by the 2014 outbreak of

Received: October 3, 2017

Accepted: December 18, 2017

Published: January 5, 2018 
EBOV in West Africa, when nearly 29000 people were infected, with over 11000 fatalities. 5 During this outbreak, the limitations of currently available diagnostic and prognostic tests led to a confirmed diagnosis in less than $60 \%$ of the cases. This outcome emphasized the need for convalescent point-ofcare diagnostic tools to identify and analyze individual survivors in order to understand the spread of the disease. ${ }^{8}$

Recent evidence from human survivors showed that recovery from EVD in humans is associated with the fast development of both cell-mediated and humoral immune responses. ${ }^{9-11}$ Hence, detection of a robust adaptive immune response may be used to predict the survival likelihoods of infected individuals. ${ }^{12}$ Traditional serological diagnostics of Ebola virus-infected patients is normally carried out using in-house laborious and expensive whole antigen enzyme-linked immunosorbent assays (ELISA), ${ }^{13}$ and takes up to $5 \mathrm{~h}$ in suitably equipped laboratories. $^{14,15}$ A promising alternative to lab-based ELISAs is lateral flow immunochromatographic technology, ${ }^{16}$ which is widely used in point-of-care diagnostic tests due to speed, cost and simplicity. ${ }^{17,18}$ Where multiple classes of molecular markers are detected on a single strip, multiplexing offers further possibilities to increase specificity and speed, and also to lower costs. ${ }^{19,20}$ Lateral flow technology usually needs to be coupled with a readout device to enable semiquantitative analysis, documentation, and data sharing. Given their computational abilities, user-friendly interfaces, and digital connectivity, smartphones are appealing portable devices by which to perform such tasks. ${ }^{21,22}$ Even the most basic models of smartphones have ample computational power, while their ubiquity, even in developing countries, gives them great potential for use as powerful healthcare tools. ${ }^{23} \mathrm{~A}$ critical sensor component is the smartphone camera, which offers high-resolution image-capture, and allows for the ready optical analysis of test strips to record results. Combining lateral flow test strips with smartphone readers has already created simple and cost-effective analytical tools. $^{24}$

Here, we designed and produced a lateral flow-based assay with specifically engineered recombinant Ebola viral proteins and combined this with a custom smartphone application (app) for semiquantitative detection of EVD immunoglobulin G (IgG) antibodies in human serum. We utilized serum samples obtained from SUDV survivors from the 2000-2001 Gulu outbreak in Uganda. The assay afforded in two platforms for either single- or multiple-analyte detection using either SUDV recombinant glycoprotein $\left(\mathrm{GP}_{1-649}\right)$ or multiple SUDV recombinant proteins (i.e., VP40, NP and $\left.\mathrm{GP}_{1-649}\right)$. In addition, we demonstrated a proof-of-concept for viral subtype identification using a second multiplex strip configuration to detect antibodies against $\mathrm{GP}_{1-649}$ of different Ebola viral species including SUDV, EBOV, and BDBV. We semiquantified all of the tested samples using the developed smartphone app including the geotagging of the collected samples in Uganda. The platform combines lateral flow strip technology with a custom-designed smartphone app, providing a rapid, robust, simple, and portable device for the specific and sensitive detection of IgG antibodies in EVD human survivors. Our system shows great potential for use as a point-ofcare test for the surveillance screening and patient management of recovered persons after Ebola disease outbreaks.

\section{RESULTS AND DISCUSSION}

Lateral Flow Test Strip Design and Development. We developed a lateral flow test strip for the detection of IgG antibodies against Ebola virus (Figure 1). The test strip design
A.
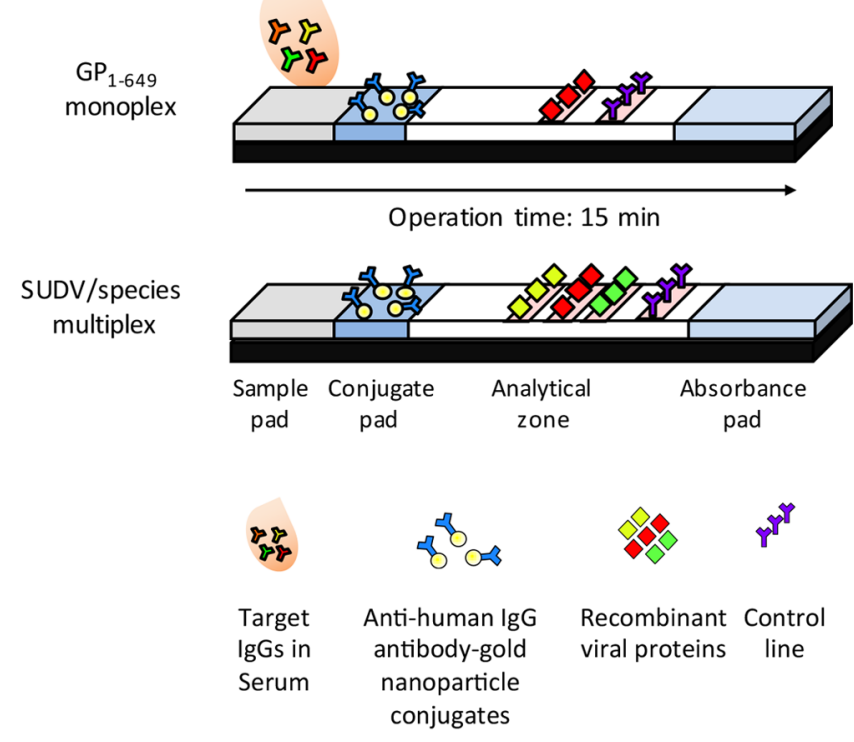

B.
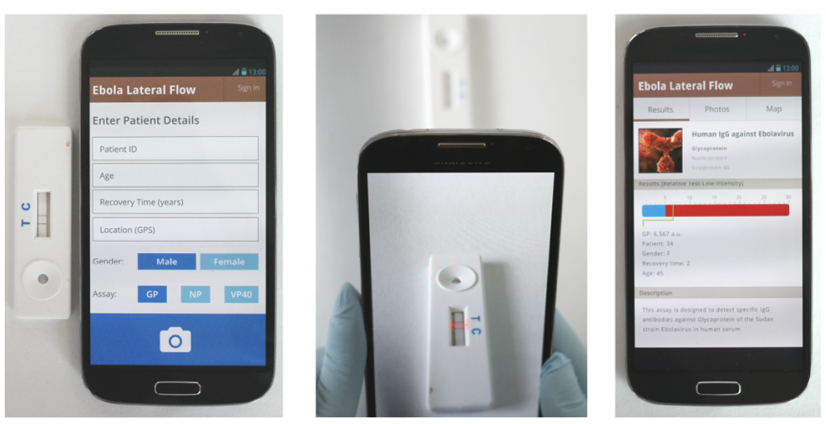

Figure 1. Smartphone lateral flow point-of-care test for Ebola virus IgG detection. (A) Lateral flow strip illustration: serum applied onto the sample pad migrates through the analytical area, and subsequently forms complexes between the labeled gold nanoparticles (AuNPs) and the target analytes. Specifically targeted IgG serum antibodies against single or multiple recombinant Ebola viral proteins bind to preprinted test lines, forming a visual red-purple line. A control line is used to validate assay function for the detection of antihuman antibody-gold nanoparticle conjugates. Assay results appear after $15 \mathrm{~min}$. (B) Illustration of the smartphone application (app) interface login window to record patient details; following submission, the analysis window opens; once the red box is aligned between the test and control lines, a tap on the screen provides the strips' analysis; result analysis window, which presents the relative intensity of the test line and determines whether the result is positive or negative based on an evaluated cutoff threshold. The window also provides a summary of patient details and a description of the test taken.

included two configurations: a single test line plotted with recombinant viral SUDV $\mathrm{GP}_{1-649}$ (referred to as $\mathrm{GP}_{1-649}$ monoplex); or three test lines plotted with SUDV recombinant viral proteins, including $\mathrm{GP}_{1-649}, \mathrm{VP} 40$ and NP, (referred to as SUDV multiplex). Assay development and optimization included gold nanoparticle (AuNP) functionalization with a secondary antibody and characterization (Supplementary Figure S1), selection of secondary antibodies (Supplementary Figure S3), determination of test line sequences (Supplementary Figure S6), and optimal sera dilution (Supplementary Figure S4). We functionalized two populations of AuNP, 20 and $40 \mathrm{~nm}$, with a 
A.
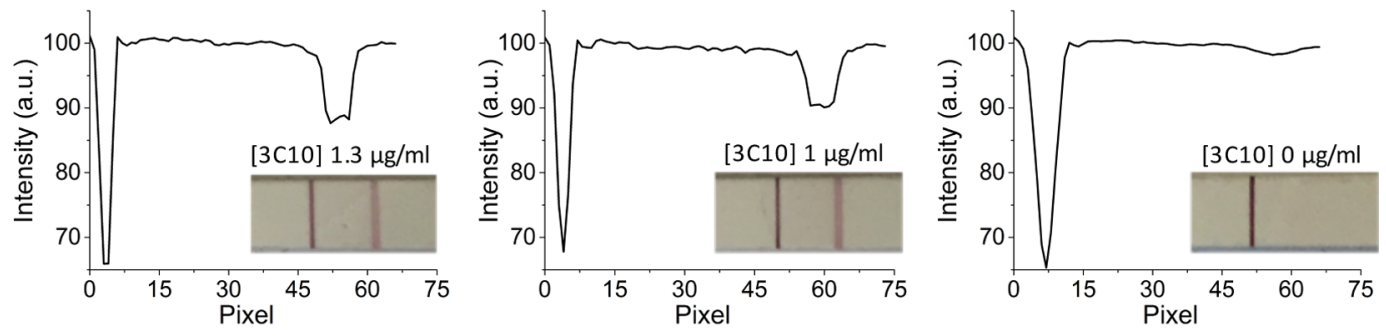

B.

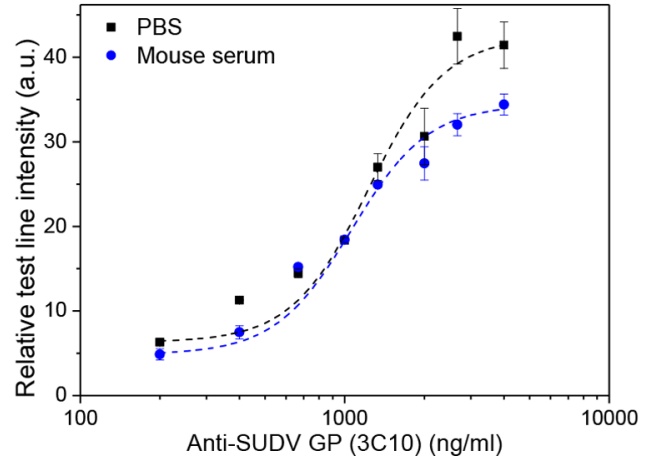

C.

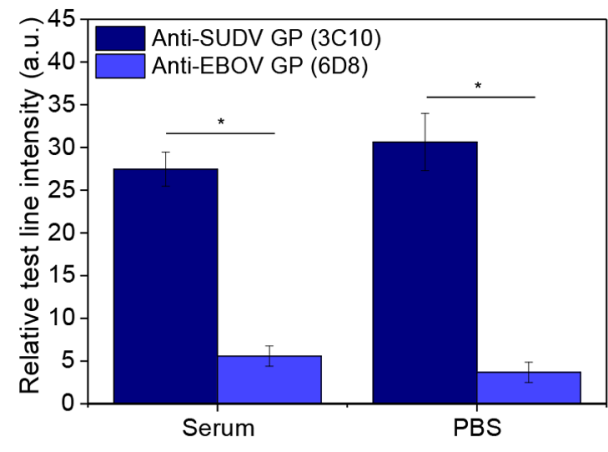

Figure 2. Assay development. (A) Assay strips and corresponding raw intensity plots quantified by the smartphone app. (B) Dose-response curves testing anti-SUDV GP (3C10) obtained in phosphate buffer and serum quantified and normalized by the smartphone app. Results are plotted and fitted to a sigmoidal curve $\left(r^{2}=0.960,0.967\right)$. Error bars indicate mean \pm standard deviation $(n=2)$. (C) Selectivity of SUDV-GP $1-649$ lateral flow strip, testing anti-SUDV GP $(3 \mathrm{C} 10)$ and anti-EBOV GP $(6 \mathrm{D} 8)(2 \mu \mathrm{g} / \mathrm{mL})$ in spiked serum and in phosphate buffer. Error bars indicate mean \pm standard deviation $(n=2)$. * indicates $p$-value $<0.05$.

secondary antibody and validated the functionalization procedure by recording a red-shift in the Surface Plasmon Resonance (SPR) peak using UV-vis spectroscopy (Supplementary Figure S1A). The volume of the functionalized particle as measured by DLS (Supplementary Figure S1B) is described in sections 2.1 and 2.2 of the Supporting Information. We observed that the 40 $\mathrm{nm}$ particles provided greater color intensity at the analytical region of the membrane compared to the $20 \mathrm{~nm}$ particles (Supplementary Figure S1C) and therefore selected the $40 \mathrm{~nm}$ AuNP to be used in all the developed test strips.

By comparing the recombinant capture viral protein blot concentration and the strip configuration, we determined $1 \mathrm{mg} /$ $\mathrm{mL}$ to be the optimal concentration for the deposition onto the nitrocellulose membrane, irrespective of protein blotting order. To identify the dynamic range of the assay, we titrated the various antibodies (anti-SUDV GP ${ }_{1-649}$, anti-BDBV GP ${ }_{1-649}$, and antiEBOV $\mathrm{GP}_{1-649}$ ) using lateral flow test strips spotted with SUDV $\mathrm{GP}_{1-649}, \mathrm{BDBV}_{\mathrm{GP}_{1-649}}$, and EBOV GP ${ }_{1-649}$, respectively. The limit of detection of the test strips was $200 \mathrm{ng} / \mathrm{mL}$ for all assay formats (as described in Supplementary section 2.2 and presented in Supplementary Figure S2B-D). The optimal assay operation time was $15 \mathrm{~min}$. The test was suitable for use up to 16 weeks postproduction when kept in low humidity and at room temperature, and showed no degradation in assay performance, using either fresh or thawed serum specimens. A total of $15 \mu \mathrm{L}$ of serum was determined as an optimal volume in a total of $20 \mu \mathrm{L}$ of total applied sample volume to achieve highest test line intensity for optimal test readout (Supplementary Figure S4). We developed the assay for serum-based use rather than whole blood mainly because of the availability of the sera biobank that was accessed for the purpose of this study. Although the separation of sera is considered a rapid and simple procedure to perform under field conditions, the use of whole blood samples, such as from a pricked finger, would simplify the operation process even more and enable "on the spot" results without any need for further equipment and facilities. Such studies for the development and adjustment of IgG detection using whole blood samples against several Ebola virus viral species are currently underway.

We translated the qualitative lateral flow test strip results into a semiquantitative readout using a tailored smartphone app developed in-house (Supplementary section 2.4 and presented in Supplementary Figure S7). The app analyses each captured image to produce an intensity plot corresponding to the color intensity of the analytical zone of the strip (Figure 2A). The average height (across the peak) of the intensity plot of the test line corresponds to the amount of the target analyte tested, and thereby provides a semiquantitative analysis. The baseline of the intensity plot is taken as the background signal (i.e., a nonanalytical zone of the lateral flow test), to which the intensity of the test line is normalized. We evaluated the performance of the assay using a positive control, namely $3 \mathrm{C} 10$ monoclonal antibodies against SUDV GP ${ }_{1-649}$, in a concentration range from $4 \mu \mathrm{g} \mathrm{mL}^{-1}$ to $200 \mathrm{ng} \mathrm{mL}^{-1}$ in PBS and in spiked serum. As presented in Figure 2B, there is a high similarity between doseresponse curves obtained in both PBS and serum, demonstrating that the assay functions in a serum environment. We evaluated the specificity of the assay using a negative control, namely $2 \mu \mathrm{g}$ $\mathrm{mL}^{-1} 6 \mathrm{D} 8$ monoclonal antibodies against EBOV-GP ${ }_{1-649}$. As shown in Figure 2C, the readout of $6 \mathrm{D} 8$ is significantly lower than $3 \mathrm{C} 10$ in PBS and in spiked serum. In addition, tests performed using thawed or fresh serum samples showed no significant difference in the assay readout (ANOVA $p$-value $<0.05)$.

Detection of IgG Immunoreactivity in Sudan Virus Human Survivors Using GP $1-649$ Monoplex Assay. We validated the 
$\mathrm{GP}_{1-649}$ monoplex assay with sera from previously infected and recovered people, referred to as "survivors", from the 2000-2001 SUDV Gulu outbreak in Uganda; noninfected locals were used as controls. This SUDV strain model is very relevant for validation as it enables the study of the long-term immunity of Ebola virus survivors.

We analyzed a total of 121 serum samples, of which 90 were obtained from survivors and 31 from noninfected controls. These samples were split into two groups, known and blind. Of these, 91 known samples (65 survivors and 26 controls) were previously analyzed by ELISA and reported elsewhere. ${ }^{25}$ A total of 30 blind serum samples ( 25 survivors and 5 controls) were obtained in the field study across Uganda and analyzed fresh within $24 \mathrm{~h}$ upon collection in Uganda Virus Research Institute. An additional 27 noninfected controls samples were used to calibrate the cutoff of $\mathrm{GP}_{1-649}$ monoplex. Noninfected EVD negative serum samples were obtained from local individual volunteers, who were either survivor family related, or had no close contact with any Ebola survivors (all samples previously tested negative by standard ELISA and PCR method as reported elsewhere, ${ }^{12}$ and clinically showed no Ebola virus infection symptoms). Careful selection of this group for the determination of the cutoff value was a key component to establishing the specificity and sensitivity of our assay, since they represented the native condition of our target population. All serum samples were also previously tested using a standardized whole antigen SUDV ELISA and a recombinant $\mathrm{GP}_{1-649}$ ELISA, which was previously reported elsewhere. ${ }^{12,25}$ Tested samples were classified as positive with levels of IgG antibodies against SUDV $\mathrm{GP}_{1-649}$ (Table 1) above the set cutoff. Out of the known samples, we determined 40 tests as positive and 51 as negative using the $\mathrm{GP}_{1-649}$ monoplex strips. Data analysis revealed that all positive

Table 1. Summary of Results from the Analysis of Sera Samples Screened with GP $_{1-649}$ Monoplex Assay, Whole SUDV ELISA, and GP ${ }_{1-649}$ ELISA

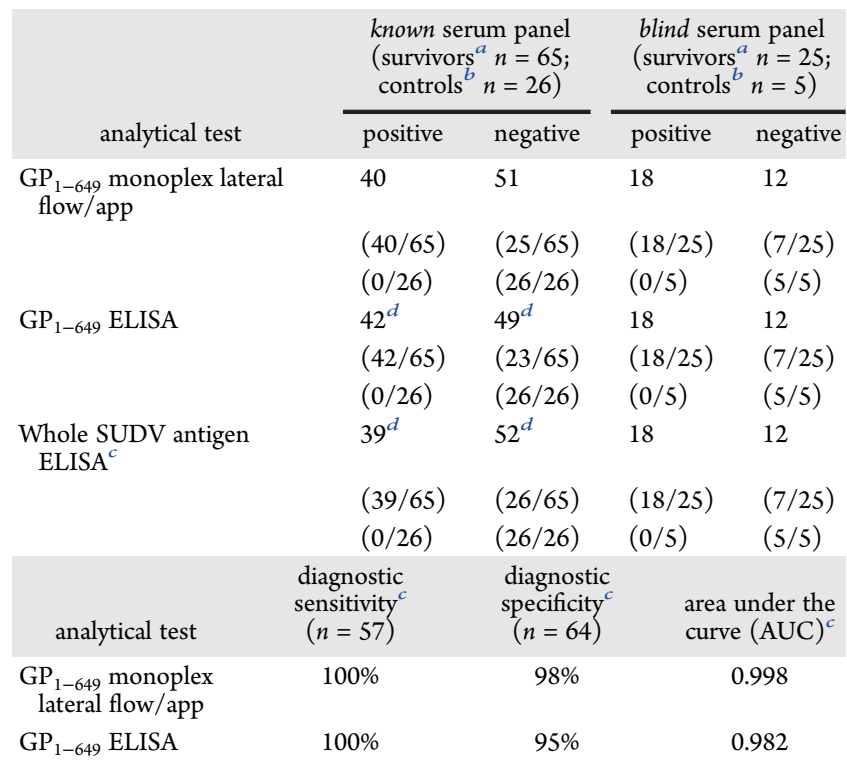

${ }^{a}$ Previously infected and diagnosed EVD patients from the 20002001 SUDV outbreak in Uganda. ${ }^{b}$ Noninfected controls obtained from closely related (family, close contact) and nonrelated EVD survivors volunteers. ${ }^{c}$ Evaluated utilizing whole SUDV antigen ELISA. ${ }^{d}$ ELISA test results for known samples, which are a subset of those measured in previous published studies. ${ }^{12,25}$ samples originated from SUDV survivors, while an additional 25 survivors tested negative. All tested noninfected controls were IgG negative. The ELISA results showed that a total of 39 and 52 samples tested IgG positive, and 42 and 49 IgG tested negative, using the gold-standard whole SUDV antigen and $\mathrm{GP}_{1-649}$ SUDV ELISA, respectively (Table 1). Box plot analysis of the known samples, Figure $3 \mathrm{~A}$, presents a similar readout distribution of the samples analysis using $\mathrm{GP}_{1-649}$ monoplex, GP 1-649 $_{1-2 L I S A}$ and SUDV ELISA. We first analyzed the blind samples using $\mathrm{GP}_{1-649}$ monoplex and then we analyzed these samples using $\mathrm{GP}_{1-649}$ ELISA and SUDV ELISA. We demonstrated 100\% correlation between $\mathrm{GP}_{1-649}$ monoplex and GP $\mathrm{GP}_{1-649}$ ELISA, as well as SUDV ELISA. Out of the 30 blind samples 18 tested as IgG positive and 12 as IgG negative samples. We evaluated the analytical parameters of the $\mathrm{GP}_{1-649}$ monoplex as compared to the gold-standard SUDV ELISA and demonstrated a correlation of $99 \%$ between the two assays, with $100 \%$ sensitivity and $98 \%$ specificity. A Receiver Operating Characteristic (ROC) analysis yielded $99.8 \%$ and $98.2 \%$ area under the curve for $\mathrm{GP}_{1-649}$ monoplex and $\mathrm{GP}_{1-649}$ SUDV ELISA, respectively (Supplementary Figure S5). In total, 64\% (58 out of 90) of the survivors demonstrated a positive IgG immune response when tested with $\mathrm{GP}_{1-649}$ monoplex, while all 31 negative controls showed no immunoreactivity. The survivors that tested with positive IgG results were in line with previous studies performed on this same cohort of survivors. ${ }^{12,25}$ Although the in-house made $\mathrm{GP}_{1-649}$ ELISA demonstrated $100 \%$ sensitivity and $95 \%$ specificity, it requires up to $5 \mathrm{~h}$ operation time using laboratory equipment.

Readout representation results using $\mathrm{GP}_{1-649}$ monoplex strips for three survivors $(\mathrm{S} 1-3)$ and two noninfected negative controls $(\mathrm{C} 1-2)$ are shown in the inset of Figure 3B. The boxplot analysis demonstrates no difference in the range of signal readout between fresh sera (blind samples, 3B) and frozen-thaw sera (known samples, 3Ai), which enabled using the previously evaluated cutoff. For the blind samples, we generated a graphical image of a surveillance map to visualize the geo-location of each patient sample collected in the field, together with the test result (positive or negative) (Figure 3C). The color intensity of the red pins corresponds to the semiquantitative immune response to $\mathrm{GP}_{1-649}$ of each tested individual. The higher magnification map represents individuals tested at the same geographical location, with the spacing between these samples being produced artificially in order to display the information on each tested individual.

Through developing a smartphone app for the semiquantitative readout of lateral flow strips, data communication and storage, and geographical tagging of the results, we have made our technology broadly available and transportable. The app was developed for an Android operating system and validated with Samsung Galaxy S4, which has high usage in central Africa. $^{26}$ The developed features of our smartphonebased assay system can potentially be used as an on-site surveillance tool, and could be readily adjusted to detect other Ebola virus species. Not only does our system enable portable and simple strip quantification, it also facilitates ready data storage, sharing, and real-time surveillance mapping. We envision that these features could provide an indispensable tool to facilitate rapid epidemiological studies of disease spread at times of critical need, such as demonstrated by the recent Ebola outbreaks in West Africa and Uganda. ${ }^{15}$ For instance, the use of the app could potentially improve the efficiency of patient screening during the acute and postrecovery stages of disease progression. It may also provide potential options for evaluating 
A.

i.

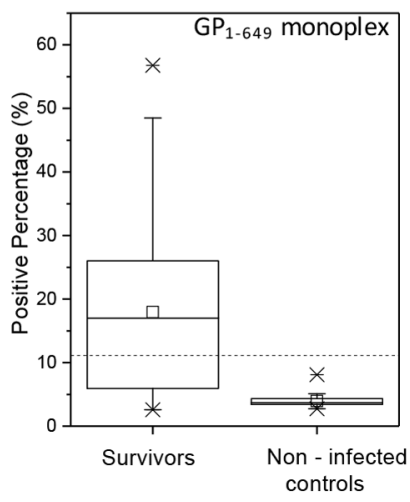

B.

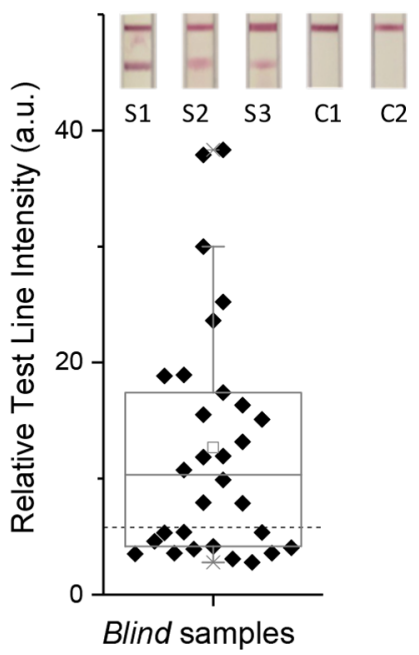

Field study in Uganda ii.

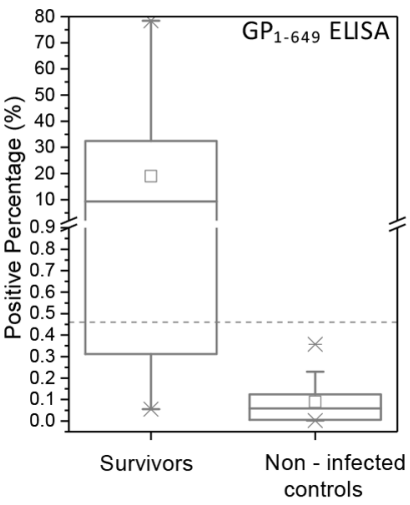

iii.

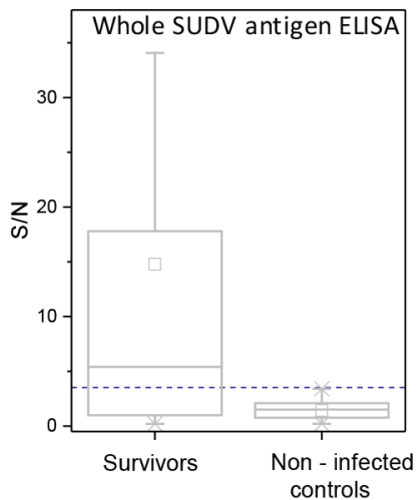

C.

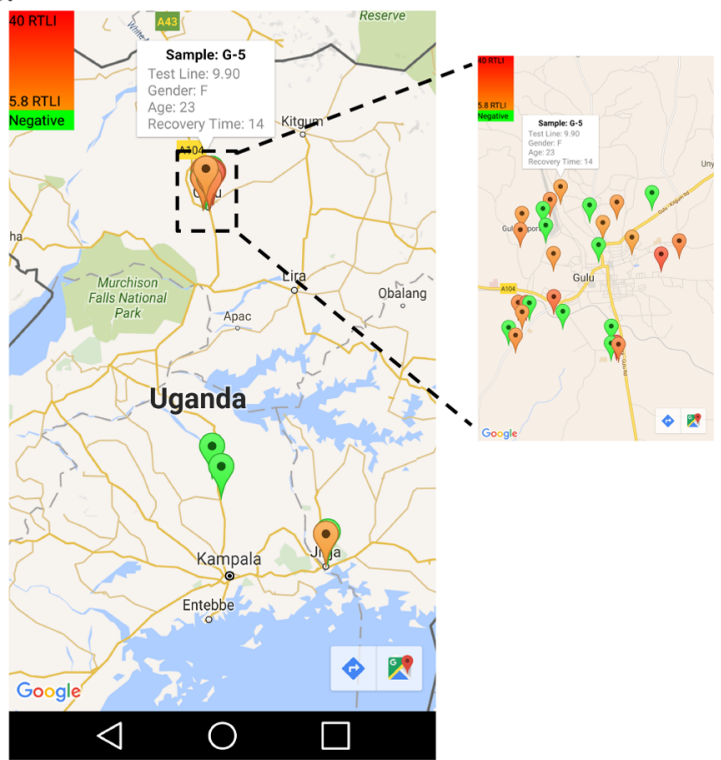

D.

i.

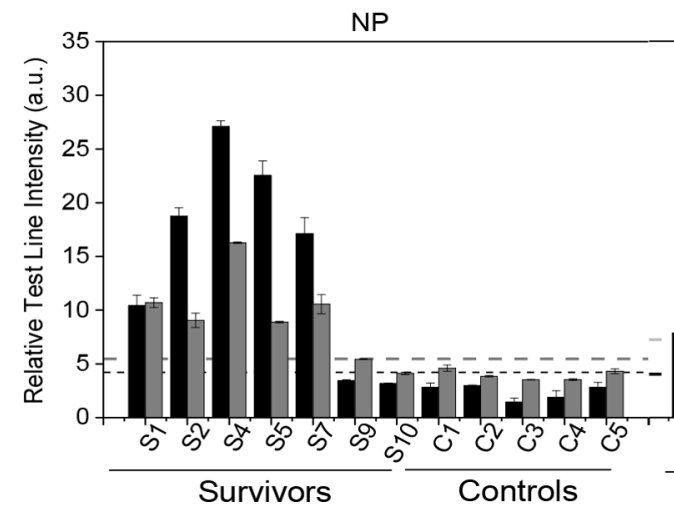

ii. VP 40

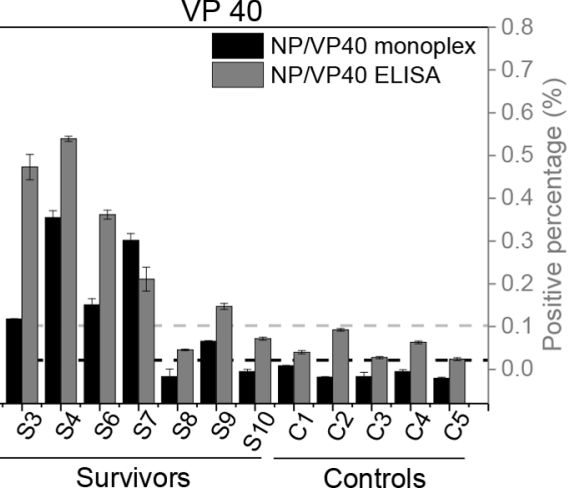

Figure 3. Monoplex SUDV platforms for the detection of IgG against single viral protein. (A) A sample readout comparison between (i) GP 1-649 monoplex, (ii) GP $_{1-649}$ ELISA, and (iii) whole SUDV ELISA. ELISA test results in (ii) and (iii) are for known samples, that are a subset of those samples measured in a previous study and published. ${ }^{12,25}$ Box plots of the known samples for each test showing the 25th, median, and 75 th percentile for the known survivors and noninfected controls. Out of the 65 analyzed survivors, 40, 42, and 39 tested positive when analyzed with (i) GP $_{1-649}$ monoplex reported in positive percentage (\%PP), (ii) GP $_{1-649}$ ELISA reported in positive percentage (\%PP) and (iii) Whole SUDV ELISA reported in signal to background noise $(\mathrm{S} / \mathrm{N})$, respectively. All 26 controls tested negative. Whiskers show the 10th and 90th percentile, and the open squares indicate the mean signal in each set. The dashed line represents the cutoff of each method calculated from the average value of the 27 controls plus three times the standard deviations. $(B-C)$ Blind sample screening. (B) Box plot of the tested samples using the GP ${ }_{1-649}$ monoplex during field study in Uganda, in the inset, lateral flow strips of three survivors (S1-3) and two noninfected controls (C1-2). (C) Map generated by on-site testing of survivors of the 2015 collection in Uganda. Red corresponds to positive and green to negative, zoomed in map 
Figure 3. continued

represents spread of the points for visual aid. A tap on each entry displays patient details. Credit: Map data (C2017 Google. (D) Detection of IgG antibodies in human sera against recombinant NP and VP40 using monoplex in relative test line intensity units (black) and positive percentage (normalized to anti-His6) ELISAs (gray). A total of 6 and 7 out of 7 survivors tested positive to IgG antibodies against (i) NP and (ii) VP40, respectively. All 5 controls tested negative. The performance of the NP and VP40 monoplex showed 100\% correlation with recombinant NP and VP40 ELISA. Black and gray dashed lines represent the assay and ELISA cut-offs. The data was averaged over 2 experimental repeats in triplicates for ELISA. Error bars represent \pm RTLI for results from lateral flow and \pm \%P for ELISA.

A. i.

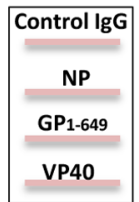

B. i.

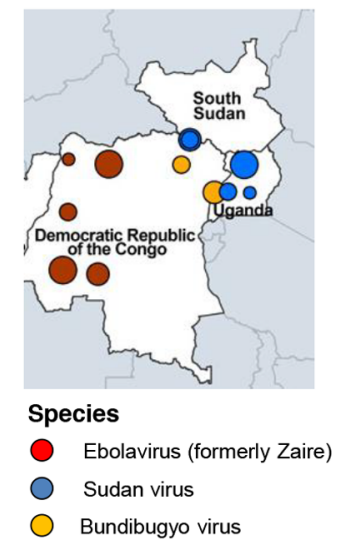

(1) ii.

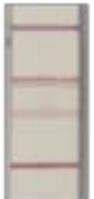

S4

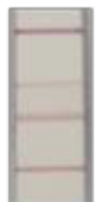

S6

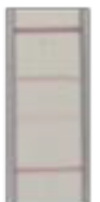

S7 ii.

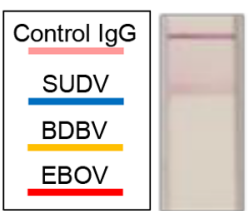

S11

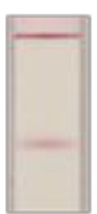

s12

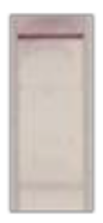

$\mathrm{S} 13$

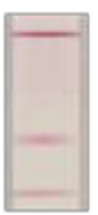

S14

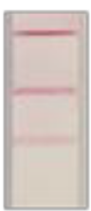

$\mathrm{S} 15$

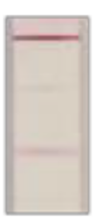

$S 16$

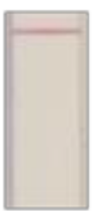

C1

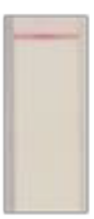

C2

Figure 4. Multiplex platforms for the detection of IgG antibodies against multiple viral proteins. (A) (i) SUDV-multiplex test strip with three test lines for simultaneous detection of IgG response to SUDV against VP40, GP ${ }_{1-649}$, and NP in sera. (ii) Capture of strips from tested sera obtained from survivors (S4, S6, S7, S9), noninfected controls (C1, C2) and (iii) monoclonal anti-His 6 as a positive control. (B) EVD species-multiplex. (i) Geographic distribution of EVD outbreaks in central Africa classified by viral species up to October $2016 .{ }^{30}$ (ii) Illustration of species multiplex test strip; test strips consist of three lines spotted with GP ${ }_{1-649}$ from SUDV, BDBV, and EBOV, control line spotted with human IgG and AuNPs conjugated to antihuman antibodies. (iii) Testing human sera from EVD survivors and noninfected controls. Six samples obtained from survivors (S11, S12, S13, S14, S15, S16) infected with different Ebola virus subtypes and two controls (C1, C2) from noninfected individuals. Visual appearance of each test line represents the detection of IgG response to specific $\mathrm{GP}_{1-649}$ from each species.

the suitability of individual survivors as plasma donors for therapeutic purposes. ${ }^{27}$

We prepared additional monoplex lateral flow test strips with a single test line for other SUDV recombinant viral proteins: NP and VP40 and directly compared the performance of these tests with receptive viral recombinant protein ELISA in a small study using 7 different and randomly selected survivors and 5 controls. The output signal of the monoplex assays is presented as a relative test line intensity obtained using the smartphone app (Figure 3D). Results are classified as positive or negative in IgG response to each protein separately (NP, VP40) based on an independent cutoff established for each protein (Figure 3D). Data analysis between the two methods demonstrates $100 \%$ semiquantitative correlation with a total of 5 survivors testing positive to IgG immunity against viral NP, and VP40. All noninfected controls tested negative to both proteins.
Detection of IgG Immunoreactivity Profile in Sudan Virus Human Survivors Using Recombinant Viral Protein Multiplex Assay. We developed a multiplex lateral flow assay using three SUDV-Gulu recombinant viral proteins: VP40, NP, and GP ${ }_{1-649}$ (as schematically presented in Figure 4A). The selection of these viral proteins is based on previous studies demonstrating their ability to elicit strong IgG humoral response in this cohort of SUDV survivors. ${ }^{12,25}$

The lateral flow test strip comprised of three test lines plotted in the following sequence (from the sample pad): VP40, GP ${ }_{1-649}$, and NP. We validated the SUDV multiplex in a pilot study with 15 samples obtained from SUDV survivors and 5 from noninfected controls. All samples were also tested using the $\mathrm{GP}_{1-649}$ monoplex, as well as individual recombinant proteins (results in line with SUDV multiplex and therefore not shown) and whole SUDV antigen ELISA. The SUDV multiplex test 
positive results are determined based on visual appearance of at least one viral protein test line. A summary of results is presented in Table 2. The multiplex results showed positive recognition of

Table 2. Summary of Serum Screening Results of SUDV Multiplex and Monoplex Lateral Assays and Whole SUDV Antigen ELISA of SUDV Survivors and Noninfected Controls

\begin{tabular}{lcccc}
\multicolumn{1}{c}{ method } & survivors $^{d}(n=15)$ & & controls $^{e}(n=5)$ \\
\cline { 2 - 3 } & positive & negative & & negative \\
SUDV Multiplex assay $^{a}$ & 13 & 2 & & 5 \\
SUDV GP $_{1-649}$ Monoplex assay $^{b}$ & 9 & 6 & & 5 \\
Whole antigen ELISA $^{c}$ & 8 & 7 & & 5
\end{tabular}

${ }^{a}$ SUDV multiplex lateral flow test strips spotted with VP40, GP ${ }_{1-649}$ and NP viral proteins ${ }^{b}$ SUDV GP ${ }_{1-649}$ lateral flow test strips ${ }^{c}$ Whole inactivated SUDV antigen ELISA ${ }^{d}$ Previously infected and diagnosed EVD patients from the 2000-2001 SUDV outbreak in Uganda. ${ }^{e}$ Noninfected controls obtained from closely related (family, close contact) and nonrelated EVD survivors volunteers.

13 out of the 15 survivor samples tested, out of which 9,10 , and 7 samples were determined as positive for $\mathrm{GP}_{1-649}, \mathrm{NP}$, and VP40, respectively. A total of 3 survivors (S4, S6, and S7) tested positive to all three viral proteins (test strips presented in Figure 4A). Moreover, a single sample obtained from S9 demonstrated relatively low but nonetheless detectable immunity against VP40 only. Representative strips of two controls obtained from noninfected volunteers $(\mathrm{C} 1-2)$ exhibited no immunoreactivity against the tested viral proteins and demonstrated the high specificity of the developed assay. In addition, we also tested monoclonal mouse anti-His ${ }_{6}$ as a control to demonstrate the position of the test lines. The $\mathrm{GP}_{1-649}$ monoplex test detected 9 positive samples, while the whole antigen IgG ELISA assay determined 8 out of the 15 survivors as IgG positive samples. All 8 positive samples in whole antigen ELISA were also positive with SUDV multiplex as well as with $\mathrm{GP}_{1-649}$ monoplex. Noninfected control samples showed no positive recognition in all three assays, as expected. The SUDV multiplex assay results demonstrated $100 \%$ sensitivity and specificity when compared to the SUDV ELISA. Interestingly, the SUDV multiplex yielded detection of a higher number of positive IgG samples in over $86 \%$ of the total tested survivors compared to $53 \%$ and $60 \%$ using whole SUDV and $\mathrm{GP}_{1-649}$ monoplex, respectively. The identification of a higher number of survivors with positive $\operatorname{IgG}$ immune recognition using the SUDV multiplex compared to the whole antigen ELISA could potentially be attributed to the concentration of purified recombinant proteins used in the recombinant format (multiplex, monoplex) compared to the total concentration of viral protein expressed in the SUDV ELISA assay (SUDV purified inactivated antigen). We hypothesize that the amount of each recombinant viral protein spotted on each test line might be higher than in the SUDV ELISA, which leads to an improved detection ability in our assay system. Further, since gamma irradiation may change the structural proteins without causing viral lysis, ${ }^{28}$ one can assume that the structure of the surface protein, GP, may be altered resulting in a reduction in binding of GP $\operatorname{IgG}$ antibodies and limiting the availability of internal viral proteins (e.g., NP) for the detection of other humoral IgGs. Although further experiments are needed, the SUDV multiplex test, which simultaneously detects the profile of three IgG antibodies, might enable an improved detection of humoral immunity during the early stages of recovery and provide an essential tool for the detection of asymptomatic infections and prevaccination assessment.

Detection and Differentiation of IgG against Multiple Species in Ebola Virus Human Survivors Using the Species Multiplex Assay. We also developed a multiplex subtype assay test for the identification of immunity to Ebola virus species SUDV, BDBV, and $\mathrm{EBOV}$ using recombinant $\mathrm{GP}_{1-649}$ viral protein. Outbreaks of these viral species from the past 10 years occurred within a distance of 1000 miles (Figure 4Bi). To demonstrate proof-of-concept, serum samples were tested from three survivors of the 2000-2001 SUDV-Gulu outbreak in Uganda (S11, S15 and S16), two survivors from the 2007 BDBV outbreak in Uganda (S12 and S14), and one survivor from the 2014-15 EBOV outbreak in West Africa (S13). Representative test strips are presented in Figure 4Biii. The results show that out of the six serum samples tested, S11, S12, and S13 demonstrated immunity to a single viral subtype (SUDV, BDBV, and EBOV, respectively). Another three survivors were positive for two different subtypes: S14 to BDBV and EBOV, S15 to SUDV and $\mathrm{BDBV}$, and S16 with responses to BDBV (stronger) and SUDV (weaker). Additionally, two noninfected control samples (C1 and C2) showed no recognition of any of the three viral subtypes, as expected. Out of the six tested survivor samples obtained from different viral outbreaks, three demonstrated a specific IgG immune response to a single viral species. The other three samples exhibited cross reactive immunity between EBOV and BDBV, which are phylogenetically closely related, ${ }^{29}$ and BDBV and SUDV, which infected within geographically similar areas. Although further validation of this platform is still needed, it is clear that such an assay could help in understanding exposure to the virus in areas such as central Africa, which has been affected by multiple EVD species.

\section{CONCLUSIONS}

The Ebola virus outbreak that occurred in 2014-2015 in West Africa saw the disease progress from a rare, localized and rural disease to a highly virulent worldwide threat. ${ }^{31}$ While many researchers do not expect another outbreak on this scale, at the time of writing, an additional outbreak has been reported in the Congo in June 2017. As a consequence, international organizations are stressing that rapid diagnostic tests are key to improving both epidemic control and patient management. ${ }^{32}$ In the light of such outbreaks, great effort has been made to develop point-of-care tests for early stage diagnosis of EVD through detection of viral antigens $s^{33,13}$ and automated molecular tests. $^{19,32}$ However, detection of antibody response to EVD infection is still performed with traditional in-house ELISA within lab-based facilities. ${ }^{34-36}$ Since most Ebola virus cases occur in rural areas, simple and portable tests for the detection of host immune response that boast comparable performance to standard lab-based immunoassays are clearly required for effective disease management. ${ }^{37}$

Our current study describes the development, optimization, and validation of a lateral flow and smartphone-based assay for the detection of IgG antibodies against EVD in human survivors. The monoplex assay is designed to detect IgG response to the GP since previous studies have shown that this protein: (a) evokes high levels of antibody production, ${ }^{38}$ and (b) boasts an important role as the basis for most currently developed vaccines. ${ }^{39}$ We validated the $\mathrm{GP}_{1-649}$ monoplex strip using a total of 90 SUDV survivors and 31 noninfected controls collected in Uganda, including known and unknown cohort samples, demonstrating $100 \%$ sensitivity and $98 \%$ specificity compared to 
standard whole antigen ELISA. Moreover, we designed a SUDV multiplex recombinant SUDV protein platform to detect and classify IgG antibodies against two additional viral proteins. This platform design is relevant because long-recovered SUDV survivors can maintain different levels of IgG humoral immunity against $\mathrm{GP}_{1-649}{ }^{1}$, while others demonstrate a complete lack of memory immunity. ${ }^{40}$ Thus, the simultaneous screening of a broader profile of humoral IgG response provided an impetus for developing this multiplex assay. Such multiplex assays could potentially increase sensitivity and specificity and allow for the identification of more exposed or recovered EVD patients compared to both the monoplex format and the traditional whole antigen ELISA currently in use. Additionally, compared to the monoplex format, the combination of multiple viral proteins is expected to better mimic the host profile of humoral immune response as it occurs during native viral infection. In the final stage of our work, we demonstrated a proof-of-concept for the detection of positive IgG immune response against the recombinant $\mathrm{GP}_{1-649}$ of several viral strains (SUDV, BDBV, and EBOV) and were able to simultaneously detect and distinguish between the immune recognition to these three Ebola species.

In addition to the advantage of detecting several potential exposures in one assay, our platform identifies human IgG antibodies against Ebola virus GP. This is especially advantageous for vaccine development, which has increased dramatically in the wake of the recent outbreaks in West Africa. Tremendous efforts are underway to fast track the development of vaccines based on immunization against Ebola GP. ${ }^{39,41}$ The immunogenicity of these vaccines is measured using antibodies from antisera by ELISA, neutralization assays for IgG response, and intracellular cytokine staining for T-cell immune response. ${ }^{14}$ The availability of a point-of-care test to detect IgG immune response against Ebola virus GP in monoplex or multiplex platforms should enable a more enhanced evaluation of vaccine efficiency under outbreak conditions. The serological platforms presented in this paper, which are based on engineered recombinant viral proteins, also offer key advantages of lower production costs, and bulk production and clearance for use in biological safety facilities (BSL-2), which are more available in remote areas. ${ }^{42}$

Overall, our current findings have addressed the critical need for faster, simpler, and more portable serology tools for detecting the deadly Ebola virus. The developed simple and portable lateral flow-based assay system has the ability to detect IgG antibodies in Ebola survivors with high sensitivity and specificity. Further work is still needed to evaluate specificity and sensitivity in larger cohort groups, vaccine evaluation studies, and assay compatibility under a wider range of environmental conditions at the point of care. It is nonetheless clear that the development and validation of the point-of-care systems as presented in this study is both timely and essential, as underscored by the fallout from the 2014-2015 Ebola virus outbreaks in West Africa.

\section{EXPERIMENTAL METHODS}

1. Ethics Statement. This study was approved by the Helsinki committees of the Uganda Virus Research Institute in Entebbe, Uganda (reference number GC/127/13/01/15); Soroka Hospital, Beer-sheva, Israel (protocol number 0263-13-SOR); and the Ugandan National Council for Science and Technology (UNCST) (registration number HS1332). L.L. and J.J.L are responsible for all ethical approvals. Written informed consent, as well as a personal health questionnaire, was completed for each subject under the supervision of L.L. and J.J.L.

2. Sample Collection. A total of 127 serum samples were tested, obtained from survivors of the 2000-2001, 2007, and 2014 EVD outbreaks in Uganda and West Africa. Subjects included confirmed survivors, according to patient PCR and ELISA results, and healthy local community members that were not infected. ${ }^{43}$ The collected samples were divided into two groups: survivors, those that were infected with the virus during the outbreak; and controls obtained from healthy volunteers that were not infected with the virus. All samples were gamma irradiated.

3. Cloning and Expression and Purification of Recombinant Viral Proteins. Purified recombinant His-tagged $\left(\mathrm{His}_{6}\right) \mathrm{GP}_{1-649}$ viral polypeptide (lacking the transmembrane domain) of SUDV, EBOV, and BDBV was prepared as previously described. ${ }^{12}$

cDNA constructs coding for SUDV-Gulu nucleoprotein (NP) and VP40 genes (GenBank AY729654) were synthesized and cloned commercially (DNA2.0) using optimized codon frequencies for E. coli. $\mathrm{A} \mathrm{His}_{6}$ was added to the $\mathrm{C}$ or $\mathrm{N}$ - terminus of $\mathrm{NP}$ and VP40 proteins, respectively.

cDNA constructs were transformed into chemically competent $E$. coli BL21(DE3) (Stratagene, Catalog \#200131) and plated onto LB agar containing $25 \mu \mathrm{g} / \mathrm{mL}$ of Kanamycin (LB-Kan). A single colony of the transformant was inoculated into $10 \mathrm{~mL}$ of LB-Kan broth and cultured at $37{ }^{\circ} \mathrm{C}$ with vigorous shaking overnight at $225 \mathrm{rpm}$. The overnight culture was diluted 1:50 into LB-Kan and grown at $37^{\circ} \mathrm{C}$ with vigorous shaking until the OD600 reached 0.6-0.8. Isopropyl-beta- $d$-thiogalactopyranoside (IPTG) was then added into the culture, which was further incubated at $37^{\circ} \mathrm{C}$ for $4 \mathrm{~h}$. Cells were harvested by centrifugation at $6000 \mathrm{rpm}$ for $20 \mathrm{~min}$ and frozen at $-80{ }^{\circ} \mathrm{C}$ until used. The pellet was resuspended in lysis buffer $\left(50 \mathrm{mM} \mathrm{NaH}_{2} \mathrm{PO}_{4}, 300 \mathrm{mM} \mathrm{NaCl}, 5 \mathrm{mM} \mathrm{b}\right.$ mercaptoethanol (b-Me) and $10 \mathrm{mM}$ imidazole, $\mathrm{pH} 8.0$ ). One $\mathrm{mg} / \mathrm{mL}$ lysozyme, $3 \mathrm{U} / \mathrm{mL}$ benzonase nuclease, and protease inhibitor cocktail (1:100) (P-8465; Sigma-Aldrich) were added to the lysis buffer and incubated for $30 \mathrm{~min}$ on ice. Cell walls were disrupted by three cycles of ultrasonication for $1 \mathrm{~min}$ at $100 \%$. The whole process was carried out on ice. The broken cells were centrifuged at $10000 \mathrm{~g}$ for $60 \mathrm{~min}$ at $4{ }^{\circ} \mathrm{C}$ to separate the soluble and insoluble proteins.

VP40 was purified from the soluble fraction. The supernatant containing His-tagged VP40 was applied onto a column containing $1 \mathrm{~mL}$ $\mathrm{Ni}-\mathrm{NTA}$ agarose resin (Qiagen) and incubated with the resin mixture for $1 \mathrm{~h}$ on a rocking platform. The column was washed with lysis buffer, and protein was eluted with a buffer consisting of $50 \mathrm{mM} \mathrm{NaH}_{2} \mathrm{PO}_{4}, 300$ $\mathrm{mM} \mathrm{NaCl}, 5 \mathrm{mM}$ b-Me and $250 \mathrm{mM}$ imidazole, $\mathrm{pH}$ 8.0. Using a Centricon $10 \mathrm{~K}$ cutoff spin filter (Millipore), the eluted protein was concentrated, and buffer was exchanged with $50 \mathrm{mM}$ Tris- $\mathrm{HCl}, 150 \mathrm{mM}$ $\mathrm{NaCl}, 5 \mathrm{mM}$ b-Me, $\mathrm{pH}$ 8.0.

NP protein was purified from the insoluble fraction or inclusion bodies. Protein expression, cell lysis, disruption, and centrifugation were carried out as described above, except that insoluble material was collected. The insoluble material was washed once with lysis buffer containing $1 \% \mathrm{v} / \mathrm{v}$ Triton $\mathrm{X}-100$, followed by two washes with lysis buffer without Triton $\mathrm{X}-100$. The insoluble material was dissolved in the denaturing solubilization buffer $(50 \mathrm{mM}$ Tris, $500 \mathrm{mM} \mathrm{NaCl}, 8 \mathrm{M}$ urea, $10 \mathrm{mM}$ imidazole, $\mathrm{pH} 8.0$ ) and mixed on a platform shaker for $c a .1 \mathrm{~h}$ at room temperature. The mixture was sonicated again as described above and centrifuged at $10000 \mathrm{~g}$ for $30 \mathrm{~min}$ at $4{ }^{\circ} \mathrm{C}$. The supernatant containing solubilized NP was collected and loaded onto $1 \mathrm{~mL}$ of NiNTA resin (Qiagen), which was pre-equilibrated with solubilization buffer. The protein was eluted from the column with solubilization buffer containing $500 \mathrm{mM}$ imidazole.

Refolding of NP protein was carried out by diluting to a uniform concentration of $0.1 \mathrm{mg} / \mathrm{mL}$ and dialyzing against refolding buffer containing $50 \mathrm{mM}$ Tris-HCl, $500 \mathrm{mM} \mathrm{NaCl} 0.5 \mathrm{M}$ L-Arginin, $50 \mu \mathrm{M}$ $\mathrm{ZnCl}_{2}, 10 \% \mathrm{v} / \mathrm{v}$ glycerol, $0.5 \mathrm{mM}$ DTT, $50 \mathrm{mM}$ imidazole and $3 \mathrm{M}$ urea, $\mathrm{pH} 8.0$, at $4{ }^{\circ} \mathrm{C}$ for $4 \mathrm{~h}$. Afterward, another dialysis step was performed against a buffer containing $50 \mathrm{mM}$ Tris- $\mathrm{HCl}, 500 \mathrm{mM} \mathrm{NaCl} 0.5 \mathrm{M} \mathrm{L}-$ Arginin, $50 \mu \mathrm{M} \mathrm{ZnCl}_{2}, 10 \% \mathrm{v} / \mathrm{v}$ glycerol, $3 \mathrm{mM}$ reduced glutathione, 0.3 $\mathrm{mM}$ oxidized glutathione, $50 \mathrm{mM}$ imidazole and $1.5 \mathrm{M}$ urea, $\mathrm{pH} 8.0$ at 4 ${ }^{\circ} \mathrm{C}$ overnight. A third dialysis step was performed against a buffer containing $50 \mathrm{mM}$ Tris- $\mathrm{HCl}, 500 \mathrm{mM} \mathrm{NaCl} 0.5 \mathrm{M} \mathrm{L}$-Arginine, $50 \mu \mathrm{M}$ $\mathrm{ZnCl}_{2}, 10 \% \mathrm{v} / \mathrm{v}$ glycerol, $1.5 \mathrm{mM}$ reduced glutathione, $0.15 \mathrm{mM}$ oxidized glutathione, $50 \mathrm{mM}$ imidazole and $0.75 \mathrm{M}$ urea, $\mathrm{pH} 8.0$, at $4{ }^{\circ} \mathrm{C}$ for $4 \mathrm{~h}$. A final dialysis step was performed against buffer containing 50 
$\mathrm{mM}$ Tris-HCl, $300 \mathrm{mM} \mathrm{NaCl}, 0.2 \mathrm{M}$ L-Arginine, $50 \mu \mathrm{M} \mathrm{ZnCl}_{2}, 10 \% \mathrm{v} / \mathrm{v}$ glycerol, $0.3 \mathrm{mM} \mathrm{DTT}$ and $0 \mathrm{M}$ urea, $\mathrm{pH} 8$, at $4{ }^{\circ} \mathrm{C}$ for $4 \mathrm{~h}$. Dialyzed protein was concentrated using a Centricon $30 \mathrm{~K}$ cutoff spin filter (Millipore).

Endotoxins were removed from the purified proteins using a ToxinEraser endotoxin removal kit (L00338, GenScript, USA) according to manufacturer's instructions. Quantification of endotoxins was performed using a ToxinSensor gel clot endotoxin assay kit (L00402, GenScript, USA) according to manufacturer's instructions. The purity of the protein samples was estimated by SDS-PAGE staining with Coomassie brilliant blue R-250. The total protein concentration was determined using a Bradford protein assay kit. Endotoxin content in the purified proteins was less than $1 \mathrm{EU} / \mathrm{mg}$ for all recombinant proteins used in the assay.

4. Lateral Flow Immunochromatographic Strip Test. 4.1. Gold Nanoparticle Conjugation. Citrate coated AuNPs of $40 \mathrm{~nm}$ diameter (selection of AuNPs size and characterization described in Supporting Information section 1.1, 1.2 and 2.1) were purchased from BBI Solutions, UK. Different AuNP conjugates were prepared with secondary antibodies including antihuman IgG (FC specific) (selection of secondary antibody described in Supporting Information 2.3), antirabbit IgG (FC specific) and antimouse IgG (FC specific) (SigmaAldrich). A $100 \mu \mathrm{L}$ volume of $100 \mu \mathrm{g} / \mathrm{mL}$ secondary antibodies in water was added to $1200 \mu \mathrm{L}$ of AuNP solution, and incubated at room temperature (shaking/rotating at $900 \mathrm{rpm}$ ) for $20 \mathrm{~min}$. Subsequently, $100 \mu \mathrm{L}$ of $1 \mathrm{mg} / \mathrm{mL}$ of bovine serum albumin (BSA) was added as a blocking agent, and incubated for an additional $20 \mathrm{~min}$ at room temperature. The particles were centrifuged for $10 \mathrm{~min}$ at $6000 \mathrm{~g}$ (the supernatant was discarded) and resuspended the AuNP in PBS pH 7.4. The concentration was adjusted to $7 \mathrm{OD}$ at a wavelength of $525 \mathrm{~nm}$ and stored at $4{ }^{\circ} \mathrm{C}$.

4.2. Strip Assembly. All materials for the lateral flow assays were obtained from Millipore (Billerica, USA). Specifically, sample and absorbent pads (CFSP001700), conjugation pads (GFCP00080000), detection pad nitrocellulose membrane (SHF2400425) and backing card (HF000MC100) were used. Test and control lines were spotted using a microspotter (Microdrop, Autodrop System AD-P-800). All spotted viral proteins were diluted with water to a final concentration of $1 \mathrm{mg} / \mathrm{mL}$. The initial concentration of VP40 and NP, 0.2 and $0.4 \mathrm{mg} /$ $\mathrm{mL}$, respectively, was adjusted to $1 \mathrm{mg} / \mathrm{mL}$ with BSA. The control lines of the strips used for human samples testing were spotted with $1 \mathrm{mg} / \mathrm{mL}$ (in water) human IgG antibodies from human serum, purchased from Sigma. The control lines of the nonhuman strips were spotted with a 1:1 mix of rabbit and mouse IgG to a final concentration of $1 \mathrm{mg} / \mathrm{mL}$. The minimum distance between spotted lines was set to be $2 \mathrm{~mm}$ using the "in-flight mode" of the microspotter. Finally, $3 \mathrm{~mm}$ single lateral flow strips were cut with a paper guillotine.

5. Human Sera Testing with Lateral Flow Strip. Two groups of samples were tested via lateral flow test strips: (1) samples that were previously collected and characterized; and (2) newly collected and tested fresh within $24 \mathrm{~h}$ after collection. Samples from the first group were stored at $-80{ }^{\circ} \mathrm{C}$ and fully thawed prior to use. In the second group, blood samples were collected into serum-separating tubes. The tubes were centrifuged at $2500 \mathrm{~g}$ for $10 \mathrm{~min}$ at room temperature. The serum was collected into cryovials. A total sera volume of $15 \mu \mathrm{L}$ was mixed with $5 \mu \mathrm{L}$ of running buffer consisting of PBS $\mathrm{pH} 7.2,0.1 \% \mathrm{v} / \mathrm{v}$ Tween-20, and 5\% w/v BSA. The sample mixture was added at the end of the nitrocellulose membrane. A $10 \mu \mathrm{L}$ volume of running buffer was added after $2 \mathrm{~min}$. Then, $10 \mu \mathrm{L}$ of AuNPs labeled with antihuman antibodies were added to the strip, and the mixture migrated along the strip membrane to the test line, which bound and immobilized the gold conjugated capture antibodies. After $5 \mathrm{~min}$, an additional wash was performed for $5 \mathrm{~min}$. The results were quantified using the smartphone app within $15 \mathrm{~min}$. A positive result following the accumulation of complex (human specific IgG bound to AuNP-mAb) was demonstrated by the appearance of a red/purple color at the test and control lines. Coloring of the control line only signified a negative test result. In the $\mathrm{GP}_{1-649}$ monoplex assay, the tested samples were classified as positive due to the presence of IgG antibodies against SUDV GP ${ }_{1-649}$. The samples tested via SUDV multiplex were classified as positive in the presence of IgG antibodies against $\mathrm{GP}_{1-649}, \mathrm{VP} 40$, or NP. To test the signal readout between frozen and fresh samples, a one-way ANOVA was conducted using the Bonferroni means comparison test, which showed no significant difference between the years at a $p$-value $<0.05$.

6. Recombinant Viral Proteins and Whole Antigen ELISA. The serum samples were analyzed using a standard ELISA protocol, following literature protocols, ${ }^{2}$ with minor adjustments. A final concentration of $2 \mu \mathrm{g} / \mathrm{mL}$ in a volume of $100 \mu \mathrm{L} /$ well of the recombinant and purified viral protein or whole inactivated SUDV antigen was pipetted into each well of a 96-well microtiter plate (MaxiSorp, Nunc). The plate was covered and incubated overnight at 4 ${ }^{\circ} \mathrm{C}$. The plates were then washed with $200 \mu \mathrm{L}$ of PBST (PBS (Sigma P4417) with 0.05\% (w/v) Tween-20 (Sigma P7949), pH 7.4. A $200 \mu \mathrm{L}$ volume per well of blocking solution of $10 \%(\mathrm{w} / \mathrm{v})$ skimmed milk was then dissolved in PBST buffer, added to the mixture, and incubated for 1 $\mathrm{h}$ at $37{ }^{\circ} \mathrm{C}$. Following incubation, plates were washed using PBST. A volume of $100 \mu \mathrm{L}$ of diluted 1:400 sera was then added and incubated for $1 \mathrm{~h}$ at $37^{\circ} \mathrm{C}$ along with a 1:1000 dilution of monoclonal antibody for the positive control. Plates were then washed with PBST, and $100 \mu \mathrm{L} /$ well of secondary antibody conjugated to HRP (diluted 1:5000) was added. After a $1 \mathrm{~h}$ incubation at $37^{\circ} \mathrm{C}$, plates were washed with PBST prior to the reading step. Oxidizing reagent and enhanced Luminol reagent solutions were inserted into the wells in a 1:1 ratio to reach a total volume of $80 \mu \mathrm{L} /$ well. Plates were read using a standard luminometer (Thermolabsystems-Luminoskac Ascent).

7. Data Analysis. The developed smartphone app (as described in Supporting Information section 1.4 and 2.4) was operated using a Samsung Galaxy S-4 smartphone to quantify the lateral flow test line. The resulting relative test line intensity was obtained by subtracting the average intensity of the test line from the average intensity of the bare membrane. The RTLI readout of the sera results of the SUDV GP ${ }_{1-649}$ were then normalized to a positive control sample. The serum ELISA result was presented as a value \%PP percentage, which was obtained as the normalized raw result divided by the positive control that contained antibodies against $\mathrm{GP}_{1-649}, 3 \mathrm{C} 10$ diluted 1:1000. The readout from the whole SUDV ELISA was normalized by the background noise $(\mathrm{S} / \mathrm{N})$. For the GP ${ }_{1-649}$ monoplex, whole SUDV ELISA, and GP ${ }_{1-649}$ ELISA, the cutoff threshold was established based on the average of the 27 tested noninfected controls with addition of $3 \times$ the standard deviation. Based on this value, the cutoff of tested survivor samples were categorized as positive or negative. To test the signal readout between frozen and fresh samples, a one-way ANOVA was conducted using the Bonferroni means comparison test, which showed no significant difference between the years at a $p$-value $<0.05$.

\section{ASSOCIATED CONTENT}

\section{Supporting Information}

The Supporting Information is available free of charge on the ACS Publications website at DOI: 10.1021/acsnano.7b07021.

AuNPs conjugation process and characterization, comparison of the line intensity using two different size AuNPs, limit of detection determination, determination of the sample volume, selection of optimal secondary antibodies and the smartphone application development, operation and output (PDF)

\section{AUTHOR INFORMATION}

\section{Corresponding Author}

*E-mail: m.stevens@imperial.ac.uk.

ORCID

Polina Brangel: 0000-0002-9295-4842

Benjamin S. Miller: 0000-0003-3032-018X

Rachel A. McKendry: 0000-0003-2018-6829

Molly M. Stevens: 0000-0002-7335-266X 


\section{Author Contributions}

P.B. and A.S. designed the study. P.B. conducted all the experimental work, carried out data interpretation and manuscript preparation and writing. A.S., J.J.L., and J.M.D. performed sample collection and preparation, and aided in data interpretation and discussions. The ELISA results of the known samples were a subset of the samples tested and analyzed by A.S. and L.L. in their previously published studies. ${ }^{12,25}$ C.P. assisted with the development and production of the lateral flow strips in R.A.M's lab and helped with discussions. B.M. developed the smartphone app with help from R.A.M. M.M.S. acknowledges the ERC Seventh Framework Programme Consolidator grant "Naturale CG" under grant agreement no. 616417. P.H. aided with discussions, data interpretation, and manuscript writing. S.G. and J.M.D provided the recombinant viral proteins and the monoclonal antibodies. R.A.M., L.L., and M.M.S. supervised the study, aided with study design, data interpretation and revised the manuscript. All authors discussed the results and commented on the manuscript.

\section{Notes}

The authors declare no competing financial interest.

\section{ACKNOWLEDGMENTS}

This work was kindly supported by the i-sense EPSRC IRC in Early Warning Sensing Systems for Infectious Disease grant (EP/K031953/1) to M.M.S. and R.A.M. A.S., J.J.L., J.M.D., and L.L. would like to acknowledge the kind support of the United States Defense Threat Reduction Agency (CB10138). Opinions, conclusions, interpretations, and recommendations are those of the authors and are not necessarily endorsed by the U.S. Army. The mention of trade names or commercial products does not constitute endorsement or recommendation for use by the Department of the Army or the Department of Defense. We also wish to thank I. Hartmann for his assistance with the graphic design of the smartphone app. P.B. acknowledges support from the Imperial College Department of Materials Kryszek/Staislawa Scholarship. We would also like to thank M. Dubois, M. Thomas, O. Varasaneux, C. Keane, A. Nogiwa Valdez, B. Pierce and S. Skeete for helpful input. Raw data are available upon request from rdm-enquiries@imperial.ac.uk.

\section{REFERENCES}

(1) Feldmann, H.; Geisbert, T. W. Ebola Haemorrhagic Fever. Lancet 2011, 377, 849-862.

(2) Kuhn, J. H. Filoviruses A Compendium of 40 Years of Epidemiological, Clinical and Laboratory Studies; Calisher, C. H., Ed.; Springer-Verlag: Vienna, 2008, Vol. 1, pp 1-413.

(3) de La Vega, M.-A.; Wong, G.; Kobinger, G. P.; Qiu, X. The Multiple Roles of sGP in Ebola Pathogenesis. Viral Immunol. 2015, 28, 3-9.

(4) Muyembe-Tamfum, J. J.; Mulangu, S.; Masumu, J.; Kayembe, J. M.; Kemp, a.; Paweska, J. T. Ebola Virus Outbreaks in Africa: Past and Present. Onderstepoort J. Vet. Res. 2012, 79, 1-8.

(5) CDC. 2014 Ebola Outbreak in West Africa I Ebola Hemorrhagic Fever. https://www.cdc.gov/vhf/ebola/outbreaks/history/summaries. html (accessed Jun 2017).

(6) WHO. Ebola Response Team. After Ebola in West Africa Unpredictable Risks, Preventable Epidemics. N. Engl. J. Med. 2016, 375, 587-596.

(7) Dhillon, R. S.; Srikrishna, D.; Sachs, J. Controlling Ebola: Next Steps. Lancet 2014, 384, 1409-1411.

(8) Clark, D. V.; Kibuuka, H.; Millard, M.; Wakabi, S.; Lukwago, L.; Taylor, A.; Eller, M. A.; Eller, L. A.; Michael, N. L.; Honko, A. N.; Olinger, G. G.; Schoepp, R. J.; Hepburn, M. J.; Hensley, L. E.; Robb, M. L. Long-Term Sequelae after Ebola Virus Disease in Bundibugyo,
Uganda: A Retrospective Cohort Study. Lancet Infect. Dis. 2015, 15, 905-912.

(9) Wong, G.; Richardson, J. S.; Pillet, S.; Patel, A.; Qiu, X.; Alimonti, J.; Hogan, J.; Zhang, Y.; Takada, A.; Feldmann, H.; Kobinger, G. P. Immune Parameters Correlate with Protection against Ebola Virus Infection in Rodents and Nonhuman Primates. Sci. Transl. Med. 2012, 4, 158 ral46.

(10) Wilson, J. A.; Hevey, M.; Bakken, R.; Guest, S.; Bray, M.; Schmaljohn, A. L.; Hart, M. K. Epitopes Involved in Antibody-Mediated Protection from Ebola Virus. Science 2000, 287, 1664-1666.

(11) Wauquier, N.; Becquart, P.; Padilla, C.; Baize, S.; Leroy, E. M. Human Fatal Zaire Ebola Virus Infection Is Associated with an Aberrant Innate Immunity and with Massive Lymphocyte Apoptosis. PLoS Neglected Trop. Dis. 2010, 4, e837.

(12) Sobarzo, A.; Perelman, E.; Groseth, A.; Dolnik, O.; Becker, S.; Lutwama, J. J.; Dye, J. M.; Yavelsky, V.; Lobel, L.; Marks, R. S. Profiling the Native Specific Human Humoral Immune Response to Sudan Ebola Virus Strain Gulu by Chemiluminescence Enzyme-Linked Immunosorbent Assay. Clin. Vaccine Immunol. 2012, 19, 1844-1852.

(13) Broadhurst, M. J.; Brooks, T. J. G.; Pollock, R. Diagnosis of Ebola Virus Disease: Past, Present, and Future. Clin. Microbiol. Rev. 2016, 29, 773-793.

(14) Vu, H.; Shulenin, S.; Grolla, A.; Audet, J.; He, S.; Kobinger, G.; Unfer, R. C.; War, K. L.; Aman, M. J.; Holtsberg, F. W. Quantitative Serology Assays for Determination of Antibody Responses to Ebola Virus Glycoprotein and Matrix Protein in Nonhuman Primates and Humans. Antiviral Res. 2016, 126, 55-61.

(15) Perkins, M. D.; Kessel, M. What Ebola Tells Us about Outbreak Diagnostic Readiness. Nat. Biotechnol. 2015, 33, 464-469.

(16) Parolo, C.; de la Escosura-Muñiz, A.; Merkoçi, A. Enhanced Lateral Flow Immunoassay Using Gold Nanoparticles Loaded with Enzymes. Biosens. Bioelectron. 2013, 40, 412-416.

(17) Posthuma-Trumpie, G. A.; Korf, J.; Van Amerongen, A. Lateral Flow (Immuno)assay: Its Strengths, Weaknesses, Opportunities and Threats. A Literature Survey. Anal. Bioanal. Chem. 2009, 393, 569-582.

(18) Parolo, C.; Merkoci, A. Paper-Based Nanobiosensors for Diagnostics. Chem. Soc. Rev. 2013, 42, 450-457.

(19) Yang, M.; Caterer, N. R.; Xu, W.; Goolia, M. Development of a Multiplex Lateral Flow Strip Test for Foot-and-Mouth Disease Virus Detection Using Monoclonal Antibodies. J. Virol. Methods 2015, 221, 119-126.

(20) Yen, C.-W.; de Puig, H.; Tam, J. O.; Gómez-Márquez, J.; Bosch, I.; Hamad-Schifferli, K.; Gehrke, L. Multicolored Silver Nanoparticles for Multiplexed Disease Diagnostics: Distinguishing Dengue, Yellow Fever, and Ebola Viruses. Lab Chip 2015, 15, 1638-1641.

(21) Zangheri, M.; Cevenini, L.; Anfossi, L.; Baggiani, C.; Simoni, P.; Di Nardo, F.; Roda, A. A Simple and Compact Smartphone Accessory for Quantitative Chemiluminescence-Based Lateral Flow Immunoassay for Salivary Cortisol Detection. Biosens. Bioelectron. 2015, 64, 63-68.

(22) Laksanasopin, T.; Guo, T. W.; Nayak, S.; Sridhara, A. a; Xie, S.; Olowookere, O. O.; Cadinu, P.; Meng, F.; Chee, N. H.; Kim, J.; Chin, C. D.; Munyazesa, E.; Mugwaneza, P.; Rai, A. J.; Mugisha, V.; Castro, A. R.; Steinmiller, D.; Linder, V.; Justman, J. E.; Nsanzimana, S.; et al. A Smartphone Dongle for Diagnosis of Infectious Diseases at the Point of Care. Sci. Transl. Med. 2015, 7, 273 rel.

(23) Martinez, A. W.; Phillips, S. T.; Carrilho, E.; Thomas, S. W.; Sindi, H.; Whitesides, G. M. Simple Telemedicine for Developing Regions: Camera Phones and Paper-Based Microfluidic Devices for Real-Time, off-Site Diagnosis. Anal. Chem. 2008, 80, 3699-3707.

(24) Yu, L.; Shi, Z.; Fang, C.; Zhang, Y.; Liu, Y.; Li, C. Disposable Lateral Flow-through Strip for Smartphone-Camera to Quantitatively Detect Alkaline Phosphatase Activity in Milk. Biosens. Bioelectron. 2015, 69, 307-315.

(25) Sobarzo, A.; Groseth, A.; Dolnik, O.; Becker, S.; Lutwama, J. J.; Perelman, E.; Yavelsky, V.; Muhammad, M.; Kuehne, A. I.; Marks, R. S.; Dye, J. M.; Lobel, L. Profile and Persistence of the Virus-Specific Neutralizing Humoral Immune Response in Human Survivors of Sudan Ebolavirus (Gulu). J. Infect. Dis. 2013, 208, 299-309. 
(26) Poushter, J. Smartphone Ownership and Internet Usage Continues to Climb in Emerging Economies. Pew Res. Cent. 2016, 1-5.

(27) Flyak, A. I.; Shen, X.; Murin, C. D.; Turner, H. L.; David, J. A.; Fusco, M. L.; Lampley, R.; Kose, N.; Ilinykh, P. A.; Kuzmina, N.; Branchizio, A.; King, H.; Brown, L.; Bryan, C.; Davidson, E.; Doranz, B. J.; Slaughter, J. C.; Sapparapu, G.; Klages, C.; Ksiazek, T. G.; et al. CrossReactive and Potent Neutralizing Antibody Responses in Human Survivors of Natural Ebolavirus Infection. Cell 2016, 164, 392-405.

(28) Wahl-Jensen, V. M.; Afanasieva, T. A.; Seebach, J.; Ströher, U.; Feldmann, H.; Schnittler, H.-J. Effects of Ebola Virus Glycoproteins on Endothelial Cell Activation and Barrier Function. J. Virol. 2005, 79, 10442-10450.

(29) Barrette, R. W.; Xu, L.; Rowland, J. M.; McIntosh, M. T. Current Perspectives on the Phylogeny of Filoviridae. Infect., Genet. Evol. 2011, $11,1514-1519$.

(30) Centre for Disease Control and Protection, V. S. P. branch. Ebola Virus Disease Distribution Map I Ebola Hemorrhagic Fever I CDC. https://www.cdc.gov/vhf/ebola/outbreaks/history/distribution-map. html.

(31) WHO. Ebola Response Team. West African Ebola Epidemic after One Year - Slowing but Not Yet under Control. N. Engl. J. Med. 2014, 141224140032008.

(32) WHO. Urgently Needed: Rapid, Sensitive, Safe \& Simple Ebola Diagnostic Tests, 2014, 1-3. http://www.who.int/mediacentre/news/ ebola/18-november-2014-diagnostics/en/ (accessed Jun 2017).

(33) Broadhurst, M. J.; Kelly, J. D.; Miller, A.; Semper, A.; Bailey, D.; Groppelli, E.; Simpson, A.; Brooks, T.; Hula, S.; Nyoni, W.; Sankoh, A. B.; Kanu, S.; Jalloh, A.; Ton, Q.; Sarchet, N.; George, P.; Perkins, M. D.; Wonderly, B.; Murray, M.; Pollock, N. R. ReEBOV Antigen Rapid Test Kit for Point-of-Care and Laboratory-Based Testing for Ebola Virus Disease: A Field Validation Study. Lancet 2015, 386, 867-874.

(34) Gire, S. K.; Goba, A.; Andersen, K. G.; Sealfon, R. S. G.; Park, D. J.; Kanneh, L.; Jalloh, S.; Momoh, M.; Fullah, M.; Dudas, G.; Wohl, S.; Moses, L. M.; Yozwiak, N. L.; Winnicki, S.; Matranga, C. B.; Malboeuf, C. M.; Qu, J.; Gladden, A. D.; Schaffner, S. F.; Stephen, F.; et al. Genomic surveillance elucidates Ebola virus origin and transmission during the 2014 outbreak. Science 2014, 345, 1369-1372.

(35) Semper, A. E.; Broadhurst, M. J.; Richards, J.; Foster, G. M.; Simpson, A. J. H.; Logue, C. H.; Kelly, J. D.; Miller, A.; Brooks, T. J. G.; Murray, M.; Pollock, N. R. Performance of the GeneXpert Ebola Assay for Diagnosis of Ebola Virus Disease in Sierra Leone: A Field Evaluation Study. PLoS Med. 2016, 13, 1-15.

(36) van Griensven, J.; Edwards, T.; de Lamballerie, X.; Semple, M. G.; Gallian, P.; Baize, S.; Horby, P. W.; Raoul, H.; Magassouba, N.; Antierens, A.; Lomas, C.; Faye, O.; Sall, A. A.; Fransen, K.; Buyze, J.; Ravinetto, R.; Tiberghien, P.; Claeys, Y.; De Crop, M.; Lynen, L.; et al. Evaluation of Convalescent Plasma for Ebola Virus Disease in Guinea. N. Engl. J. Med. 2016, 374, 33-42.

(37) Flint, M.; Goodman, C. H.; Bearden, S.; Blau, D. M.; Amman, B. R.; Basile, A. J.; Belser, J. A.; Bergeron, É.; Bowen, M. D.; Brault, A. C.; Campbell, S.; Chakrabarti, A. K.; Dodd, K. A.; Erickson, B. R.; Freeman, M. M.; Gibbons, A.; Guerrero, L. W.; Klena, J. D.; Lash, R. R.; Lo, M. K.; et al. Ebola Virus Diagnostics: The US Centers for Disease Control and Prevention Laboratory in Sierra Leone, August 2014 to March 2015. J. Infect. Dis. 2015, 212, S350-S358.

(38) Qiu, X.; Audet, J.; Wong, G.; Pillet, S.; Bello, a.; Cabral, T.; Strong, J. E.; Plummer, F.; Corbett, C. R.; Alimonti, J. B.; Kobinger, G. P. Successful Treatment of Ebola Virus-Infected Cynomolgus Macaques with Monoclonal Antibodies. Sci. Transl. Med. 2012, 4, 138ra81138 ra81.

(39) Kanapathipillai, R.; Henao Restrepo, A. M.; Fast, P.; Wood, D.; Dye, C.; Kieny, M.-P.; Moorthy, V. Ebola Vaccine-an Urgent International Priority. N. Engl. J. Med. 2014, 371, 2249-2251.

(40) Sobarzo, A.; Eskira, Y.; Herbert, A. S.; Kuehne, A. I.; Stonier, S. W.; Ochayon, D. E.; Fedida-Metula, S.; Balinandi, S.; Kislev, Y.; Tali, N.; Lewis, E. C.; Lutwama, J. J.; Dye, J. M.; Yavelsky, V.; Lobel, L. Immune Memory to Sudan Virus: Comparison between Two Separate Disease Outbreaks. Viruses 2015, 7, 37-51.
(41) Henao-Restrepo, A. M.; Longini, I. M.; Egger, M.; Dean, N. E.; Edmunds, W. J.; Camacho, A.; Carroll, M. W.; Doumbia, M.; Draguez, B.; Duraffour, S.; Enwere, G.; Grais, R.; Gunther, S.; Hossmann, S.; Kondé, M. K.; Kone, S.; Kuisma, E.; Levine, M. M.; Mandal, S.; Norheim, G.; et al. Efficacy and Effectiveness of an rVSV-Vectored Vaccine Expressing Ebola Surface Glycoprotein: Interim Results from the Guinea Ring Vaccination Cluster-Randomised Trial. Lancet 2015, 386, 857-866.

(42) Risi, G. F.; Bloom, M. E.; Hoe, N. P.; Arminio, T.; Carlson, P.; Powers, T.; Feldmann, H.; Wilson, D. Preparing a Community Hospital to Manage Work-Related Exposures to Infectious Agents in Biosafety Level 3 and 4 Laboratories. Emerging Infect. Dis. 2010, 16, 373-378.

(43) Lamunu, M.; Lutwama, J. J.; Kamugisha, J.; Opio, A.; Nambooze, J.; Ndayimirije, N.; Okware, S. Containing a Haemorrhagic Fever Epidemic: The Ebola Experience in Uganda (October 2000 - January 2001). Int. J. Infect. Dis. 2004, 9, 27-37. 